Article

\title{
Preparation of PVA Fluorescent Gel and Luminescence of Europium Sensitized by Terbium (III)
}

\author{
Yifan Wei ${ }^{1}$, Zhengquan Fu ${ }^{1}$, Hao Zhao ${ }^{1}$, Ruiqi Liang ${ }^{1}$, Chengyu Wang ${ }^{1,2}$, Di Wang ${ }^{1,2, *}$ () and \\ Jian $\mathrm{Li}^{1,2}$ \\ 1 Collage of Material science \& engineering, Northeast Forestry University, Harbin 150040, China; \\ ivan98cn@163.com (Y.W.); fzq1999fzq@163.com (Z.F.); chill_blue@163.com (H.Z.); cosmiclrq@163.com (R.L.) \\ 2 Key Laboratory of Biobased Material Science \& Technology (Ministry of Education), Northeast Forestry \\ University, Harbin 150040, China \\ * Correspondence: diwang1030@nefu.edu.cn
}

Received: 24 March 2020; Accepted: 10 April 2020; Published: 12 April 2020

\begin{abstract}
Polyvinyl alcohol (PVA) gel has a very wide range of applications in agriculture, military, industry, and other fields. As a widely used water-soluble polymer, PVA has good mechanical properties, excellent spinnability, good hydrophilicity, remarkable physical and chemical stability, good film formation, is non-polluting, and exhibits good natural degradation and biocompatibility. It is an ideal gel preparation material. Incorporation of rare-earth elements into PVA polymers can be used to prepare rare-earth luminescent gel materials. Results show that the luminescent efficiency of complexes is mainly related to their structure, ligand substituents, synergists, and the electronic configuration of doped rare-earth ions. Fluorescent gel films were prepared by adding europium, terbium, and europium/terbium co-doped into PVA, and their fluorescence properties were compared and analyzed. It was found that, in addition to the above factors, the sensitization of terbium to europium, and the fluorescence-quenching effect of hydroxyl groups, will influence the fluorescence properties. This has opened a new route for the application of rare-earth materials and may have value in the field of new materials.
\end{abstract}

Keywords: PVA gel; europium; terbium; sensitization; quenching

\section{Introduction}

In recent years, there has been a great interest in the development of new synthetic hydrogels and hydrogel composites, which can be attributed to their unique combination of properties, including biocompatibility, permeability, hydrophilicity, and low friction coefficient [1-5]. Polyvinyl alcohol (PVA) also has good light transparency. According to existing studies, PVA can be used as the raw material for the synthesis of artificial corneas [6-8]. Most of PVA fluorescent films are used as luminescent materials and detection materials in recent research. One type of luminescent material is embedded with phosphors containing rare earth minerals using soluble sodium silicates (water glass), hydroxyethyl cellulose (HEC) and PVA as adhesives. It was demonstrated that the converter films can be recycled by dissolving the films in water at room temperature for HEC and PVA and at $60^{\circ} \mathrm{C}$ for the sodium silicates [9]. By contrast, the preparation of PVA gels, which require only natural cooling, is simple. Fluorescence efficiency was improved by introducing organic ligands. The hydrogels have a unique response time to different ammonia environments through a fluorescence quenching pattern. This process can be identified by the naked eye, so there are potential applications for fluorescent hydrogels in ammonia detection. 
At present, there are many surface-treatment methods of PVA, such as silanization, electrospinning, electrochemical oxidation, solution casting, immersion precipitation, and the sol-gel method. Different treatment methods have different effects on the PVA surface [10-14]. The silane coupling agent can not only react with the hydroxyl group in an inorganic substance, but also interact with the long molecule in an organic substance, so it can bridge the two phases and connect them $[15,16]$. Inorganic material is simple to prepare, and, e.g., wood is modified with rare-earth complexes to produce PVA fluorescent film material, which not only maximizes the characteristics of PVA, but also endows it with new fluorescence properties, so that the modified PVA can be better applied in interior decoration, handicraft production, and other uses.

Rare earth metals are oxytropic, and have a variety of coordination modes. The chelation-metal center binding mode is usually used to regulate the structural changes and exhibit catalytic activity for different epoxy substrates [17]. The effect of ligand-sensitized central ion luminescence is called the antenna effect. The complexes centered on rare earth ions are called luminescence centers, and their increasing concentration will lead to an increase in fluorescence intensity in the absence of other influences. When the complex has a larger conjugate plane and a more-rigid structure, energy loss during ligand transfer is reduced and the fluorescence efficiency increases [18].

The fluorescence properties of rare-earth (lanthanide) elements have become a hot research field. Emission color is largely determined by the lanthanide ion, but also depends on the ligand. Most research in this area has been limited to inorganic compounds [19]. Rare-earth elements can be used as excellent luminescent materials, but their molar absorption coefficient is small, and their luminous efficiency is low. Other scientific experiments have shown that the tetratetralorthosilprivate can be used as the matrix to prepare the gel. The process of preparing the gel is extremely complicated, require many drying steps, and takes a long time [20]. By contrast, the preparation of PVA gels, which require only natural cooling is simple. The effects of temperature, time, Eu/Tb ratio, and complex concentration on fluorescence performance were investigated. The reason for choosing Eu and $\mathrm{Tb}$ is that europium and terbium are already widely used as fluorescent materials, and because red and green fluorescence are primary colors, a potentially useful factor for fluorescent materials. In addition, it was also found that terbium had a sensitization effect on europium fluorescence and excessive hydroxyl content had a quenching effect on fluorescence. The $\mathrm{Eu} / \mathrm{Tb}$ ratio determines when sensitization reaches its maximum.

Other studies on rare earth fluorescence materials, organic ligands were used and PVA was used as the matrix. The fluorescence sensitization of terbium to europium and the fluorescence quenching effect of hydroxyl groups were investigated. In this paper we also study hydrolysis-modified PVA and explore the new technology of PVA inorganic functionalization. Our objective is to provide a basic theoretical foundation that has not been currently established in PVA-rare-earth-complex functional composite luminescence materials research. According to the experimental results, the thermal stability of the modified complex was improved after crosslinking with PVA, so increasing temperature did not affect the fluorescence intensity of the film. Therefore, as a recyclable fluorescent material, this product has potential utilization value.

\section{Experimental Details}

\subsection{Preparation of Silane-Modified Eu/Tb Co-Doped Complexes}

First, aminopropyltriethoxysilane (Huawei chemical co. LTD, Beijing, China) (KH550) (3.5419 g) and phthaloyl chloride (TCI development co. LTD, Shanghai, China) (1.6241 g) were dissolved in dichloromethane $(10 \mathrm{~mL})$ separately in beakers $(50 \mathrm{~mL})$ as solution 1 and 2 . Next, the two solutions were slowly mixed in an ice bath into beaker 1 and sealed, followed by magnetic stirring at room temperature for $2 \mathrm{~h}$. The stirred liquid was placed in an oven at a temperature of $45^{\circ} \mathrm{C}$ for $75 \mathrm{~min}$ to vaporize the $\mathrm{HCl}$ that was produced during the reaction to make sure the complex is neutral. The yellowish viscous liquid was obtained as the silane-modified ligand and dissolved in DMF (10 mL). 
Then, europium nitrate hexahydrate (Huawei chemical co. LTD, Beijing, China) $(0.4461 \mathrm{~g})$ and terbium nitrate hexahydrate (Huawei chemical co. LTD, Beijing, China) $(0.4530 \mathrm{~g})$ were dissolved in DMF $(10 \mathrm{~mL})$. The two solutions were mixed and stirred in a water bath $\left(70^{\circ} \mathrm{C}\right)$ for $4 \mathrm{~h}$, and silane-modified $\mathrm{Eu} / \mathrm{Tb}$ co-doped complexes were obtained [21]. Silane-modified europium and terbium complexes were produced in the same way, and, by changing the molar ratio of $\mathrm{Eu} / \mathrm{Tb}$, silane-modified $\mathrm{Eu} / \mathrm{Tb}$ co-doped complexes were produced in different molar ratios (Eu:Tb=1:1, 1:2, 1:3, 1:4, 1:5, 1:6, 1:7, 1:8, 1:9, 2:1, 3:1, 4:1, 5:1, 6:1, 7:1, 8:1, and 9:1). The structural formulas are shown in Figure 1.
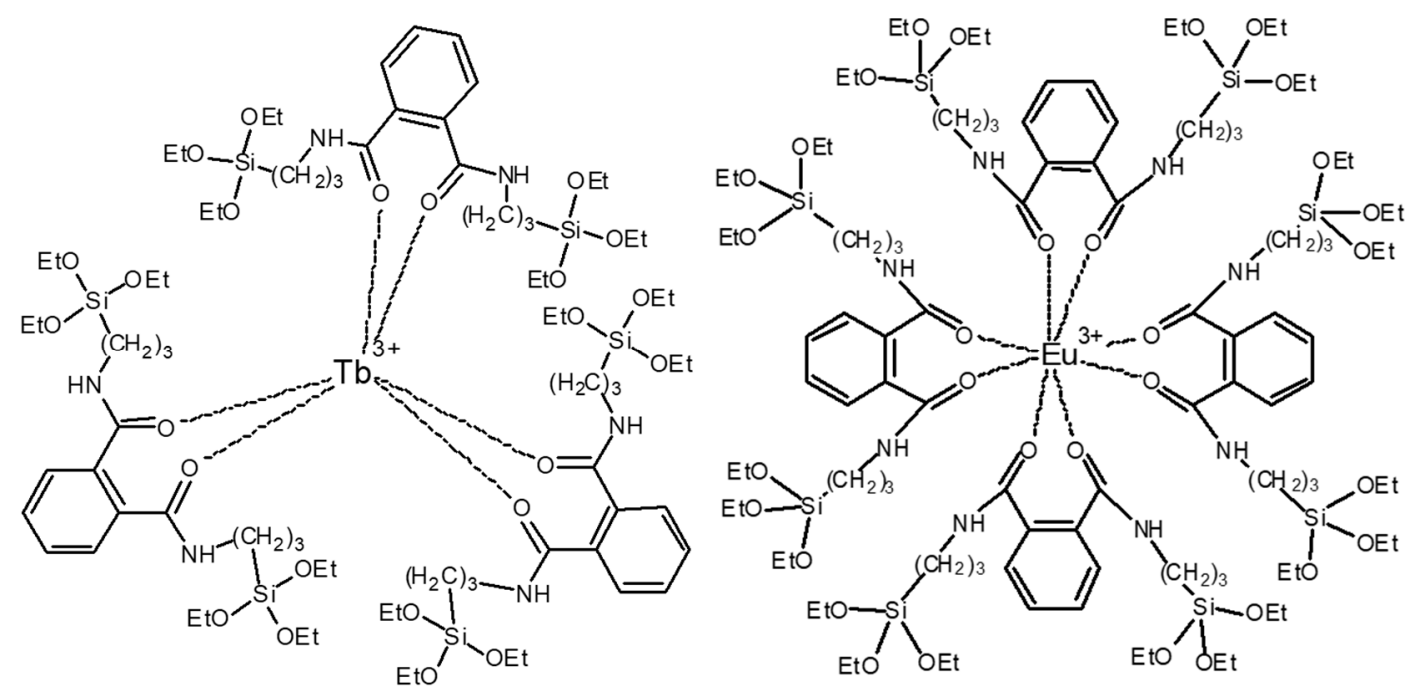

Figure 1. The structural formulas of $\mathrm{Tb}$ and Eu complexes.

\subsection{Preparation of PVA Fluorescent Gel}

First, PVA (Guangfu fine chemical research institute, Tianjin, China) (0.5 g) was dissolved in distilled water $(4.5 \mathrm{~mL})$ in a three-neck round-bottom flask $(100 \mathrm{~mL})$ and stirred in a water bath $\left(90^{\circ} \mathrm{C}\right)$ to dissolve PVA completely. Next, boric acid $(0.05 \mathrm{~g})$ was dissolved in distilled water $(1 \mathrm{~mL})$ in a beaker and added into the flask. Boric acid (BA) induced the formation of crosslinking through hydrogen bonding with polymers followed by strong ionic bonding between hydroxyl groups of PVA and borate ions of BA and the solution is still neutral after testing by $\mathrm{pH}$ indicator paper [22]. Then, the silane-modified $\mathrm{Eu} / \mathrm{Tb}$ co-doped complexes $(0.04 \mathrm{~mol} / \mathrm{L})$ were added in a series of volumes $(1,2, \ldots$, $9 \mathrm{~mL}$ ) into the flask. Afterwards, the system reached homogeneity, and was reacted for a series of times $(15,30,45,60,75,105$, and $120 \mathrm{~min})$ at a series of temperatures $(45,50,55,60,65,70,75,80,85,90$, and $\left.95{ }^{\circ} \mathrm{C}\right)$. After a period of reaction, the solution in the flask was poured into a home-made rectangular glass dish $(10 \mathrm{~cm} \times 20 \mathrm{~cm})$ forming a gel and vaporizing the solvent.

\subsection{Structural Characterization and Performance Testing}

The size and morphology of the PVA fluorescent gel were obtained by scanning electron microscopy (SEM) (FEI, Netherlands) using a Quanta instrument operated at an acceleration voltage of $160 \mathrm{kV}$. The chemical groups of the PVA fluorescent gel were detected by a Fourier-transform infrared (FTIR) spectroscopy (FTIR-650) (Gangdong technology co. LTD, Tianjin, China). Thermogravimetric analysis (TGA) (Netzsch instruments co. LTD, Germany) of samples was conducted using a thermogravimetric analyzer (TG209F3). The X-ray-diffraction (XRD) (FEI, Netherlands) patterns of the gel were analyzed using an XRD-6100 instrument (Shimadzu Corp., Japan). Excitation and emission spectra were recorded using an LS55 fluorescence spectrophotometer (PE, America) at room temperature. The surface chemical composition of PVA fluorescent gel was determined by an energy-dispersive X-ray detector (FEI, Netherlands). 


\section{Results and Discussion}

\subsection{Structural Analysis}

The Fourier-transform infrared (FTIR) spectra of the modified $\mathrm{Eu}^{3+} / \mathrm{Tb}^{3+}$ complex, PVA fluorescent gel, and PVA gel presented in Figure 2 contain several peaks, which represent several stretching vibrations $-\mathrm{C}=\mathrm{O}, \mathrm{N}-\mathrm{H}$, and $\mathrm{C}-\mathrm{Si}-$ at approximately 1715,1471 , and $1070 \mathrm{~cm}^{-1}$, respectively. The peak positions and their assignments are presented in Table 1 . The bands observed at 1715 and $1741 \mathrm{~cm}^{-1}$ are due to the stretching relaxation of the $\mathrm{C}=\mathrm{O}$ and $\mathrm{N}-\mathrm{H}$ bonds, respectively.The phthaloyl chloride standard infrared spectrogram, in which the peaks of $\mathrm{C}=\mathrm{O}$ and $\mathrm{C}-\mathrm{Cl}$ bonds are supposed to exist at 1770 and $790 \mathrm{~cm}^{-1}$, respectively, indicates that the phthaloyl chloride reacted with the silane coupling agent containing amino to form acylamino, proving that the modified ligand exists. The $\mathrm{C}-\mathrm{Si}$ band observed at approximately $1070 \mathrm{~cm}^{-1}$ is attributed to the fact that the C-Si bond did not break during the ligand formation. The band observed at $715 \mathrm{~cm}^{-1}$ is the infrared characteristic peak of RE-O $\left(\mathrm{RE}=\mathrm{Eu}^{3+}, \mathrm{Tb}^{3+}\right)$ which reveals that the oxygen in acyl forms a coordinate bond with the rare earth ion. Through infrared-absorption spectral analysis, due to the rare-earth-ion structures being similar in certain kinds of modified complex ligands, a similar infrared characteristic peak is shown.

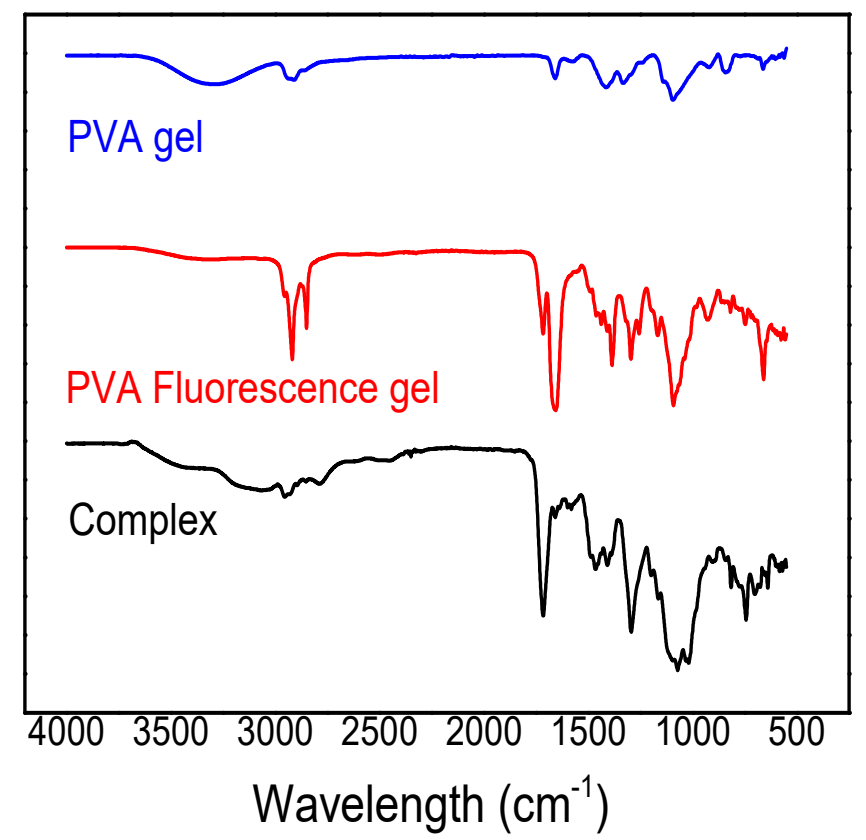

Figure 2. Fourier-transform infrared spectra (FTIR) of modified $\mathrm{Eu}^{3+} / \mathrm{Tb}^{3+}$ complex.

Table 1. Energy-dispersive X-ray-spectroscopy results for $\mathrm{Tb} / \mathrm{Eu}$ fluorescent gel.

\begin{tabular}{ccc}
\hline Element & wt. $\%$ & at. $\%$ \\
\hline $\mathrm{C}$ & 51.50 & 66.85 \\
$\mathrm{~N}$ & 10.96 & 12.20 \\
$\mathrm{O}$ & 12.73 & 12.40 \\
$\mathrm{Na}$ & 03.68 & 02.50 \\
$\mathrm{Si}$ & 03.33 & 01.85 \\
$\mathrm{Cl}$ & 07.15 & 03.14 \\
$\mathrm{Eu}$ & 03.90 & 00.40 \\
$\mathrm{~Tb}$ & 06.75 & 00.66 \\
\hline
\end{tabular}

Figure 3 shows the XRD curve for PVA gel and $\mathrm{Eu}, \mathrm{Tb}$, and $\mathrm{Tb} / \mathrm{Eu}$ fluorescent gels. As shown in Figure 3 one peak around $2 \theta=20^{\circ}$ appeared, corresponding to the (101) plane of PVA [23]. However, the peak broadened and shifted for the samples containing a complex, and it weakened with the 
addition of more complexes. Peaks at approximately $2 \theta=31^{\circ}$ and $45^{\circ}$ correspond to the (200) and (220) planes of $\mathrm{NaCl}$, respectively [24].

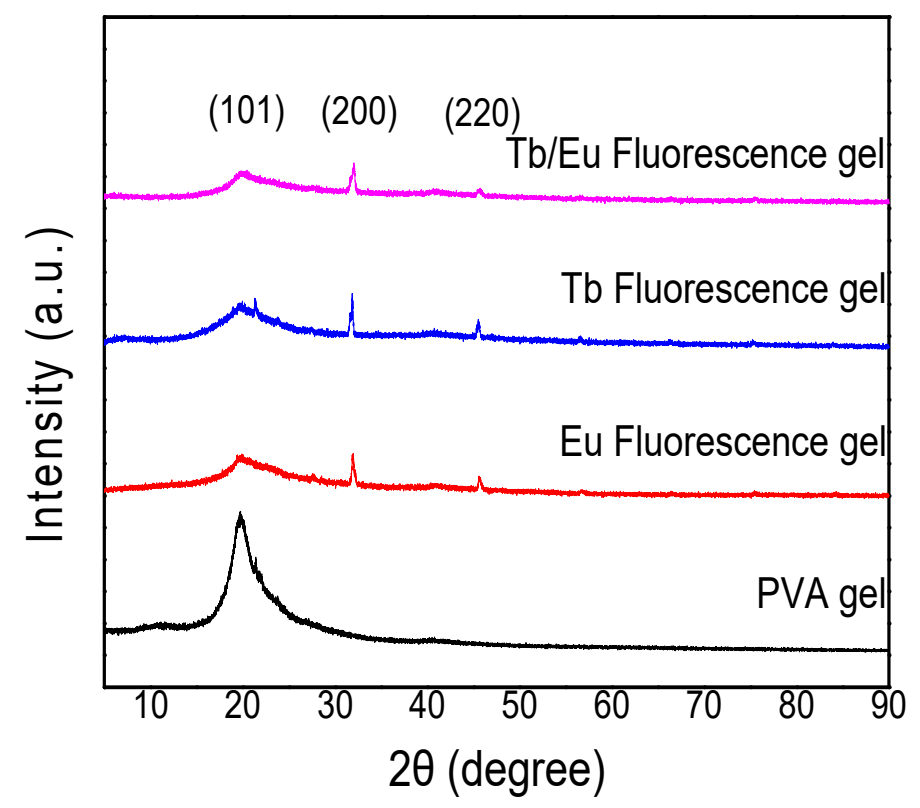

Figure 3. X-ray-diffraction (XRD) curves for PVA gel and $\mathrm{Eu}, \mathrm{Tb}$, and $\mathrm{Tb} / \mathrm{Eu}$ fluorescence gels.

The morphology of the PVA hydrogel and PVA fluorescent gel was studied by SEM. The SEM images presented in Figure 4 reveal the PVA hydrogel is composed of many tiny particles on the surface. Based on the results of energy-dispersive X-ray-spectroscopy analysis (Table 1), it is suspected that the particles on the surface are $\mathrm{NaCl}$. Table 1 also shows the compositions of the PVA hydrogel and PVA fluorescent gel, and the main components in PVA hydrogel are $\mathrm{C}$ and $\mathrm{O}$. The table further shows the detailed contents and reveals that the main components are $\mathrm{C}$ and $\mathrm{O}$, which are from the PVA hydrogel. The $\mathrm{Cl}$ and $\mathrm{Na}$ are from phthaloyl chloride and the silane coupling agent, and they are also attached to the PVA spatial structure. Furthermore, according to Table 1, the mass ratio of europium and terbium to silicon is 3.2 , but this is different from the theoretical value, which indicates that the distribution of modified europium/terbium co-doped complexes in PVA films was not uniform.

\subsection{Fluorescence Spectra}

Hydrogels are a kind of material composed of water and a high-molecular polymer possessing a three-dimensional cross-linked network structure. They exhibit good water absorption and water retention and are considered efficient luminescent hosts for rare-earth ions to produce phosphors emitting a variety of colors. The electron transition forms of rare earth ions are $\mathrm{f}-\mathrm{f}, \mathrm{f}-\mathrm{d}$ and charge transition. Most rare earths have $\mathrm{f}-\mathrm{f}$ transitions, which are forbidden transitions. In order to overcome the shortcomings of low molar absorption coefficient and low luminous efficiency, rare earth ions can coordinate with organic ligands with high absorption coefficient to form complexes. The center ion of complex could fluoresce, and the organic ligand transfers the absorbed energy to the center rare earth ion in the form of a non-radiative transition to sensitize it to emit characteristic fluorescence. Figure 5 shows the photoluminescence (PL) excitation spectra of the modified rare-earth-complex $\left(\mathrm{Eu}^{3+}: \mathrm{Tb}^{3+}=1: 1\right)$ powders. Figure 5 a shows the emission spectra of the modified rare-earth complex upon setting the excitation wavelength to $350 \mathrm{~nm}$. The emission spectrum is dominated by the $5 \mathrm{D}^{4}-7 \mathrm{~F}^{6}$ $(492 \mathrm{~nm})$ and $5 \mathrm{D}^{4}-7 \mathrm{~F}^{5}(547 \mathrm{~nm})$ electron transitions of $\mathrm{Tb}^{3+}$ with a maximum at $547 \mathrm{~nm}$. Thus, this peak is selected as the characteristic peak. Figure $5 \mathrm{~b}$ shows the emission spectra of the modified rare-earth complex upon setting the excitation wavelength to $390 \mathrm{~nm}$. The emission spectrum is dominated by the 
$5 \mathrm{D}^{0}-7 \mathrm{~F}^{1}(594 \mathrm{~nm})$ and $5 \mathrm{D}^{0}-7 \mathrm{~F}^{2}(619 \mathrm{~nm})$ electron transitions of $\mathrm{Eu}^{3+}$ with a maximum at $619 \mathrm{~nm}$ [25-31]. Therefore, $619 \mathrm{~nm}$ was selected as the characteristic peak.
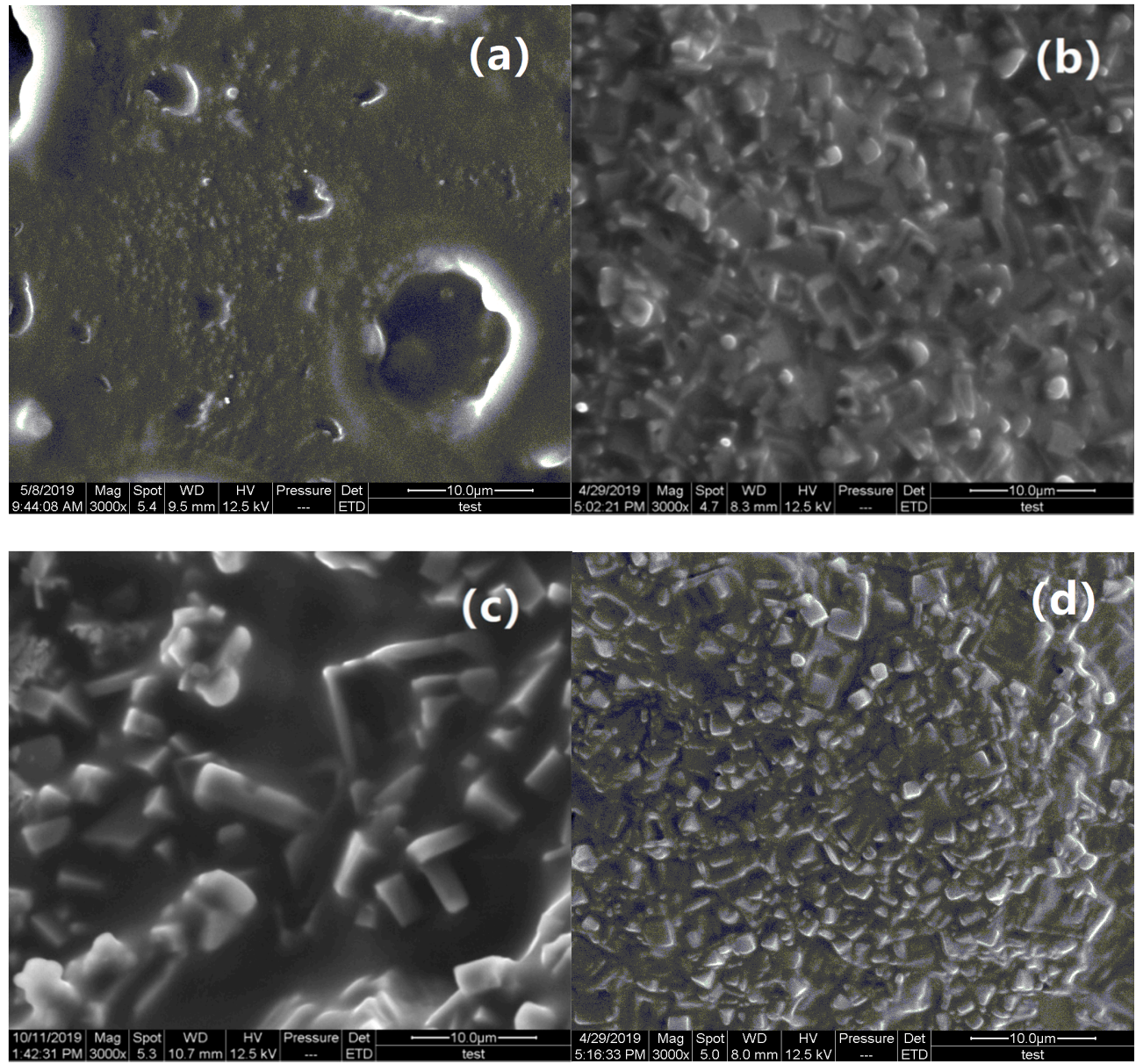

Figure 4. SEM images of (a) PVA gel, (b) Tb fluorescent gel, (c) Eu fluorescent gel, and (d) Eu/Tb fluorescent gel.

Figure 6 presents the fluorescence emission intensities of the PVA fluorescent gel with different concentrations by controlling the temperature $\left(90{ }^{\circ} \mathrm{C}\right)$, reaction time $(45 \mathrm{~min})$, and $\mathrm{Eu}^{3+}: \mathrm{Tb}^{3+}$ ratio. The figure indicates that the intensity of the characteristic peak of the PVA fluorescent gel first increases and then decreases with increasing volume of the modified rare-earth complex. The intensity of $\mathrm{Eu}^{3+}$ has a maximum at $8 \mathrm{~mL}$ and that of $\mathrm{Tb}^{3+}$ has a maximum at $7 \mathrm{~mL}$. It is clear that the fluorescence emission intensity of PVA fluorescence gel does not increase linearly with reaction concentration, indicating that fluorescence quenching may occur in the reaction. It can be inferred from this phenomenon that, along with increasing concentration, the $\mathrm{Eu}^{3+}$ and $\mathrm{Tb}^{3+}$ contents and fluorescence intensity also increase because of the increase in the number of luminescence centers. By the time a certain concentration is added, the increase of hydroxyl concentration will lead to fluorescence quenching [32]. By comparing the fluorescence emission intensity of $\mathrm{Eu}^{3+}$ only and $\mathrm{Tb}^{3+}$ only, the fluorescence emission intensity of $\mathrm{Eu}^{3+}$ increases and that of $\mathrm{Tb}^{3+}$ decreases. This is because the fluorescence quenching of $\mathrm{Tb}^{3+}$ occurs as the $\mathrm{Eu}^{3+}$ content increases, and the $\mathrm{Eu}^{3+}$ intensity will increase when the $\mathrm{Tb}^{3+}$ content increases because of the sensitized fluorescence from $\mathrm{Tb}^{3+}[33,34]$. 

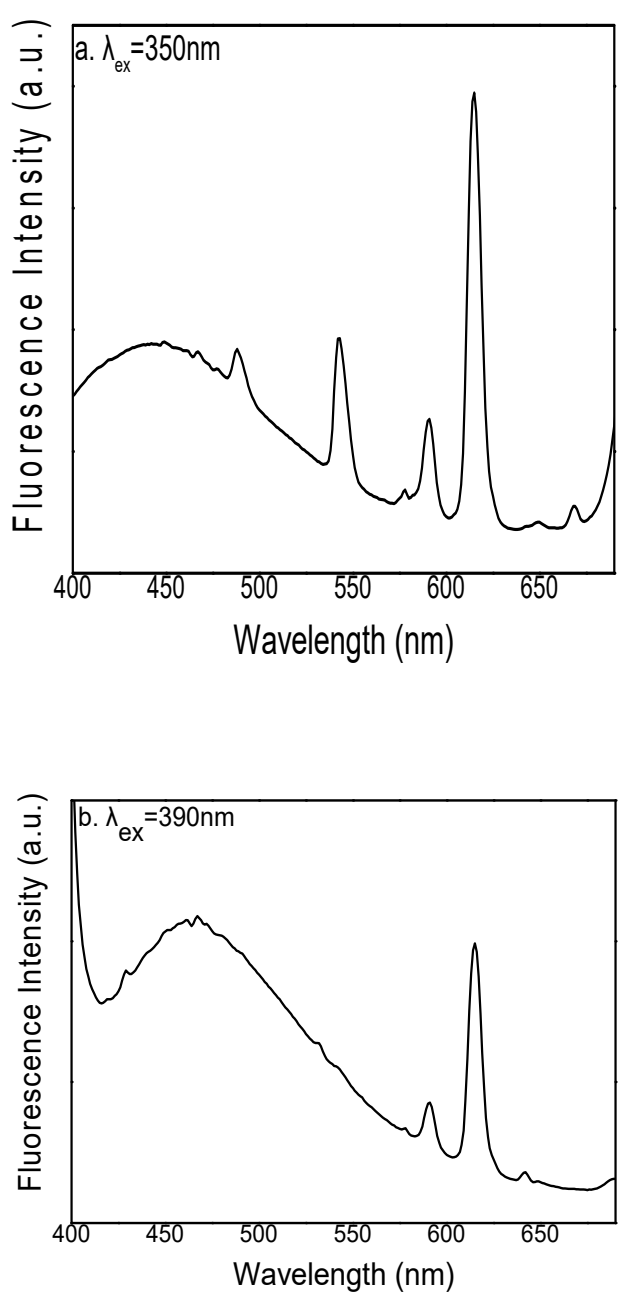

Figure 5. Photoluminescence (PL) excitation spectra of modified rare-earth complexes with wavelengths (a) $350 \mathrm{~nm}$, (b) $390 \mathrm{~nm}$.

Figure 7 shows the fluorescence emission intensity of the PVA fluorescent gel for different reaction times by controlling the temperature, reaction concentrations, and $\mathrm{Eu}^{3+}: \mathrm{Tb}^{3+}$ ratios. The figure shows that the intensity of PVA fluorescent gel at the characteristic peak did not change much after $45 \mathrm{~min}$ and then decreased slightly after $105 \mathrm{~min}$. Because of the sensitization of $\mathrm{Tb}$, the fluorescence intensity of Eu increased by 117\%, 409\%, 311\%, 237\%, 207\%, 583\%, 138\% and 202\% (an average of 210\%) and the fluorescence intensity of $\mathrm{Tb}$ decreased by $58 \%, 56 \%, 70 \%, 54 \%, 70 \%, 70 \%$ and $77 \%$ (an average of $65 \%$ ). It can be inferred from the above phenomenon that, after the reaction time reaches $45 \mathrm{~min}$, the fluorescence intensity stops rising. The silicon hydroxyl group was hydrolyzed from the ethoxy group in the modified co-doped complexes, so $\mathrm{Eu}^{3+}$ and $\mathrm{Tb}^{3+}$ are fixed in the PVA gel owing to the fact that the silicon hydroxyl groups bind to the hydroxyl groups in the PVA gel. With the consuming of the complex, the reaction rate decreases, and the increased quantity of the hydroxyl group with time leads to fluorescence quenching due to the excess of complexes. 

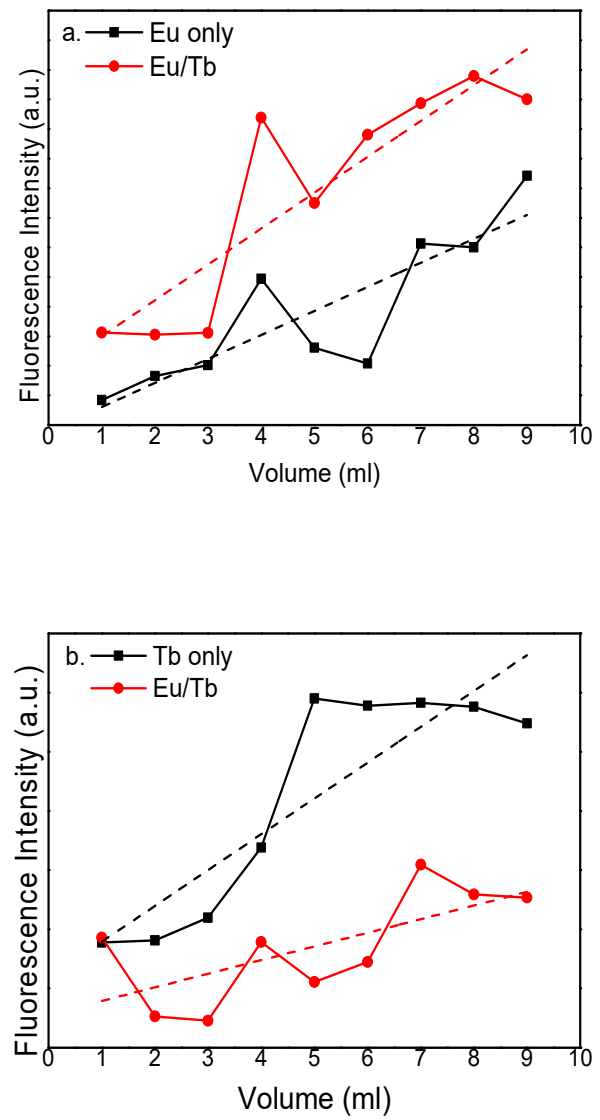

Figure 6. Fluorescence emission intensity of PVA fluorescent gel of (a) Eu and (b) Tb at different concentrations.

Figure 8 presents the fluorescence emission intensity of PVA fluorescent gel at different reaction temperatures by controlling the reaction time, reaction concentration, and $\mathrm{Eu}^{3+}: \mathrm{Tb}^{3+}$ ratio. It is shown that the intensity of PVA fluorescent gel at the characteristic peak reaches its maximum when the temperature reaches $80^{\circ} \mathrm{C}$, but the fluorescence intensity decreases gradually with increasing temperature. The collision between complex molecules is more intense, resulting in energy loss, which reduces the energy-transfer efficiency of the ligand to the central ion, reduces the condensation reaction with the hydroxyl group on PVA, and results in the decrease of the fluorescence intensity of PVA fluorescent gel. By calculating the average of fluorescence intensity, the fluorescence intensity of doped europium was 2.4 times higher than before. Terbium, however, exhibited a $45 \%$ reduction in fluorescence intensity.

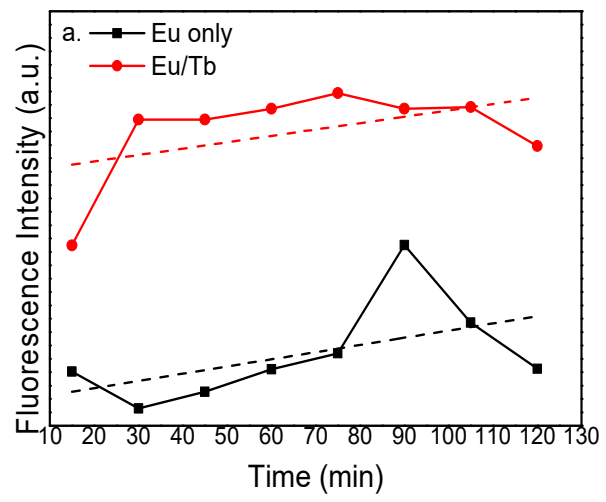

Figure 7. Cont. 


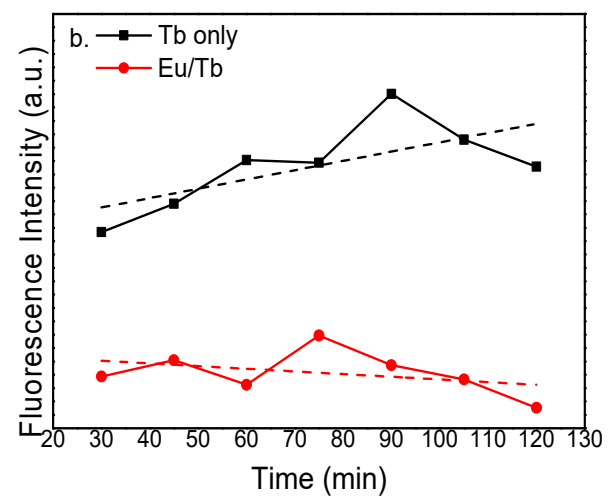

Figure 7. Fluorescence emission intensity of PVA fluorescent gel of (a) Eu and (b) Tb for different reaction times.
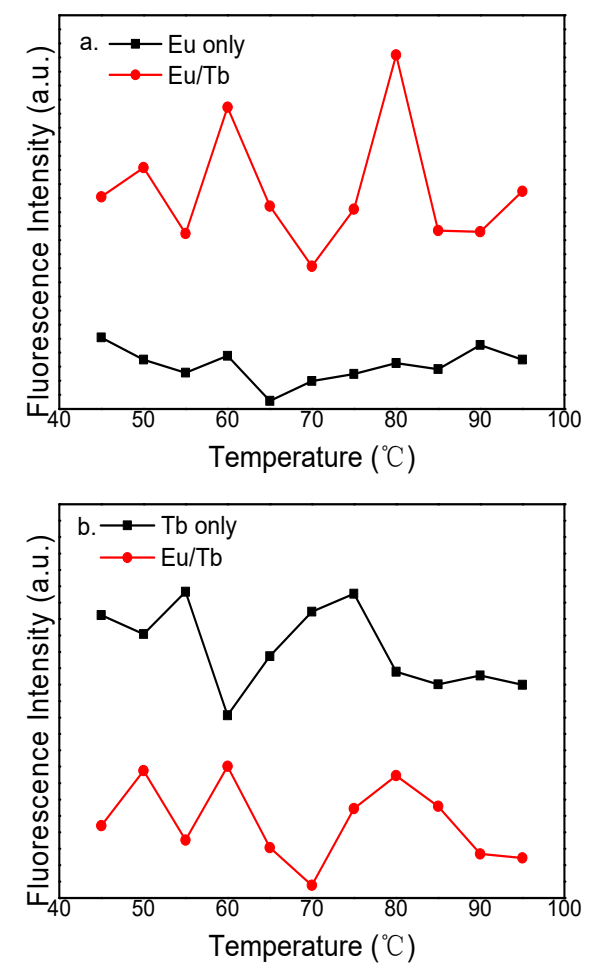

Figure 8. Fluorescence emission intensity of PVA fluorescent gel of (a) Eu and (b) Tb at different reaction temperatures.

Figure 9 presents the fluorescence emission intensity of the PVA fluorescent gel with different $\mathrm{Eu}^{3+}: \mathrm{Tb}^{3+}$ ratios by controlling the reaction time and reaction concentration. It is shown that the fluorescence intensity of $\mathrm{Eu}^{3+}$ first decreased and then increased with the addition of $\mathrm{Tb}^{3+}$ when the water content remained unchanged. It can be inferred that $\mathrm{Tb}^{3+}$ binds to ligands more easily when the $\mathrm{Tb} 3+: \mathrm{Eu} 3+$ ratio is less than $4\left(\mathrm{Eu}^{3+}\right.$ needs four ligands and $\mathrm{Tb}^{3+}$ only five); when the $\mathrm{Tb}^{3+}: \mathrm{Eu}^{3+}$ ratio is greater than 4 , the sensitization of water to salt is stronger, which leads to an increase in fluorescence.

Figure 10 presents the thermogravimetric (TG) and differential (DTG) curves of PVA gel and PVA fluorescent gel. The thermal decomposition of PVA gel is divided into three stages: (1) removal of water molecules from the PVA; (2) elimination of the branched chain of PVA from the backbone, along with generation of water molecules and acetic acid molecules, with a mass reduction of approximately $51 \%$; and (3) the decomposition of the PVA backbone, producing small molecules, such as acetaldehyde and butenol, with a mass reduction of approximately $18 \%$. After thermal decomposition, approximately $13 \%$ of decomposition products remain. 


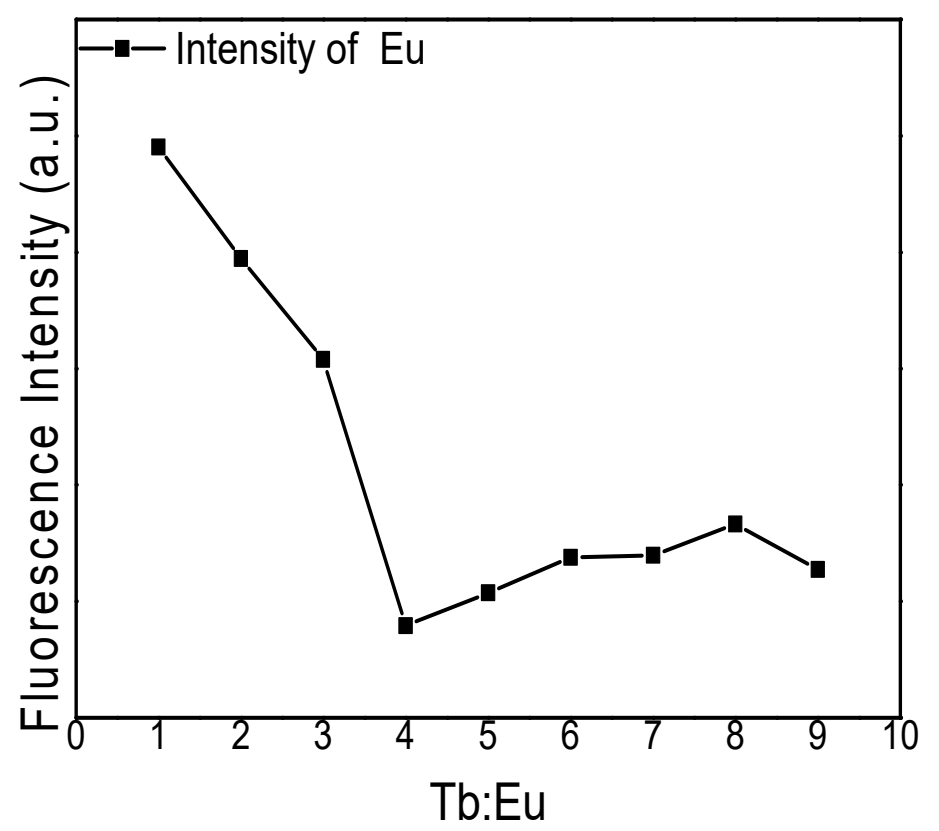

Figure 9. Fluorescence emission intensity of PVA fluorescence gel for different $\mathrm{Eu}^{3+}: \mathrm{Tb}^{3+}$ ratios.
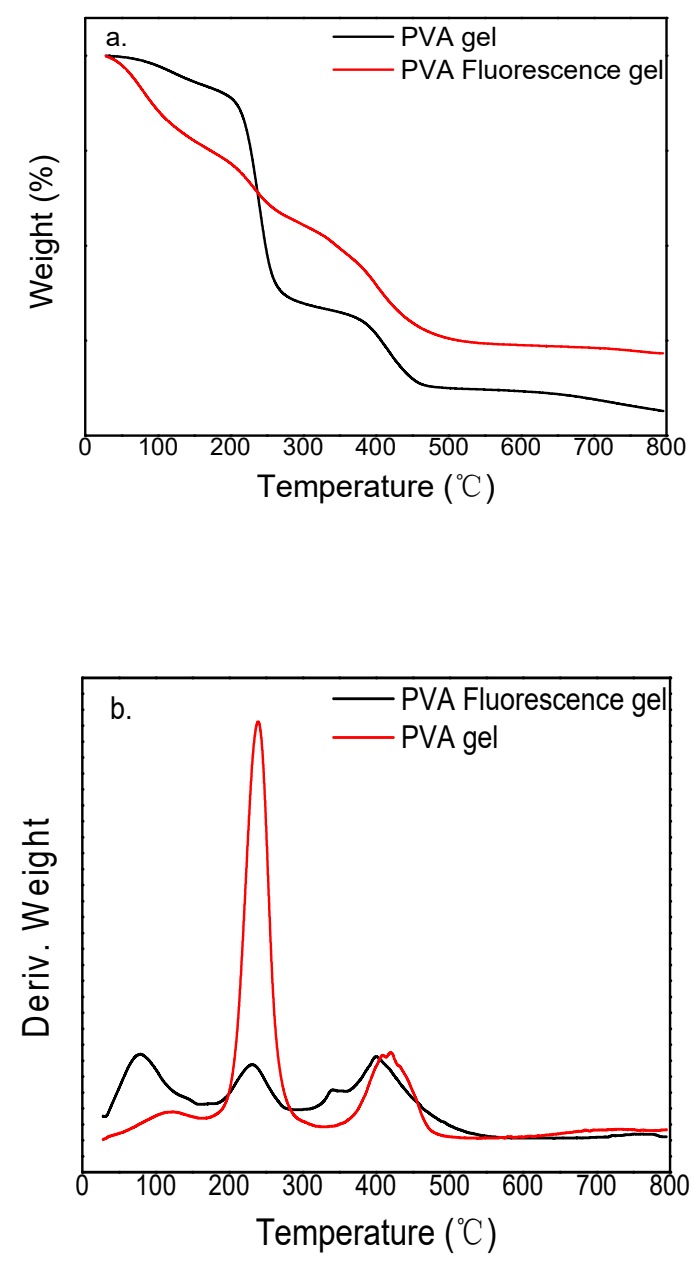

Figure 10. Thermogravimetric (TG) (a) and differential thermogravimentric (DTG) (b) curves of PVA gel and PVA fluorescent gel. 
The thermal decomposition process of PVA fluorescent gel is similar to that of PVA gel. However, in the second stage, in addition to water and acetic acid molecules, the Eu/Tb co-doped complex is produced with a mass reduction of approximately $15 \%$, possibly because the complex reduces the amount of branched-chain decomposition by binding to the PVA branched chain. The mass loss in the third stage was approximately $22.5 \%$. After thermal decomposition, approximately $24 \%$ of the decomposition products remained, and the excess could be co-doped complexes.

PVA gel began to undergo thermal decomposition at approximately $200{ }^{\circ} \mathrm{C}$, slightly higher than the decomposition temperature of PVA fluorescent gel, indicating that the combination of modified complexes and PVA reduced the thermal stability of PVA gel.

\section{Conclusions}

In summary, a fluorescent gel was prepared by combining rare-earth ions with ligands and using PVA as the carrier. Through the combination of rare-earth elements and ligands, the energy of rare-earth ions is transferred to the central rare-earth ions through the triplet states of the ligands, and the rare-earth ions are stimulated to emit light. The interaction between europium and terbium was studied by doping europium and terbium, and it was found that in the process of energy transfer terbium ions could effectively increase the luminescence intensity of europium ions and play a sensitization role. Meanwhile, an excessive amount of hydroxyl group was found to quench fluorescence. We believe that this series of PVA fluorescent gels has good luminescence and thermal properties and has a certain application value in the field of new energy resources.

Author Contributions: Data curation, H.Z.; formal analysis, Z.F.; project administration, D.W.; supervision, C.W., D.W. and J.L.; visualization, R.L.; writing—original draft, Y.W.; writing—review \& editing, Y.W. All authors have read and agreed to the published version of the manuscript.

Acknowledgments: This work was supported by the National Natural Science Foundation of China [Grant number 31770593], China Postdoctoral Science Foundation [Grant number 160750], National College Student Innovation and Entrepreneurship Training Program, Northeast Forestry University, China [Grant number 201810225004].

Conflicts of Interest: The authors declare that there is no conflict of interests regarding the publication of this article.

\section{References}

1. Wu, Z.Q.; Han, X.E.; Su, X.; Zhang, L.L. Recent advances in the luminescent materials of rare-earth complexes. J. Chem. Intermed. 2011, 8, 9-15.

2. Franville, A.C.; Zambon, D. Synthesis and optical features of a europium organic-inorganic silicate hybrid. J. Alloy. Compd. 1998, 275, 831-834. [CrossRef]

3. Tsaryuk, V.; Zolin, V.; Legendziewicz, J. The structure of ligand and effects of the europium luminescence excitation. J. Lumin. 2003, 102, 744-750. [CrossRef]

4. Wu, Y.C.; Zhu, L.; Wang, H.S. Synthesis of rare earth complexes of $\mathrm{Eu}^{3+}$ and $\mathrm{Dy}^{3+}$ ions and their luminescent properties. J. Chem. Res. 2014, 25, 29-32.

5. Stammen, J.A.; Williams, S.; Ku, D.N. Mechanical properties of a novel PVA hydrogel in shear and unconfined compression. Biomaterials 2001, 22, 799-806. [CrossRef]

6. Myung, D.; Duhamel, P.E.; Cochran, J.R. Development of hydrogel-based keratoprostheses: A materials perspective. Biotechnol. Prog. 2010, 3, 735-741. [CrossRef]

7. Wang, J.; Gao, C.; Zhang, Y. Preparation and in vitro characterization of BC/PVA hydrogel composite for its potential use as artificial cornea biomaterial. Mater. Sci. Eng. 2010, 30, 214-218. [CrossRef]

8. Mansur, H.S.; Oréfice, R.L.; Mansur, A.A. Characterization of poly (vinyl alcohol)/poly (ethylene glycol) hydrogels and PVA-derived hybrids by small-angle X-ray scattering and FTIR spectroscopy. Polymer 2014, 45, 7193-7202. [CrossRef]

9. Hämmer, M.; Gassmann, A.; Reller, A.; von Seggern, H.; Gutfleisch, O.; Stauber, R.; Zimmermann, J. Recyclable Phosphor Films: Three Water-Soluble Binder Systems Enabling the Recovery of Phosphor Powders in White LEDs. J. Electron. Mater. 2019, 48, 2294-2300. [CrossRef] 
10. Zhang, Y.; Li, H.; Li, H. Preparation and characterization of modified polyvinyl alcohol ultrafiltration membranes. Desalination 2006, 192, 214-223. [CrossRef]

11. Li, Y.; Lin, X. Simultaneous electroanalysis of dopamine, ascorbic acid and uric acid by poly (vinyl alcohol) covalently modified glassy carbon electrode. Sens. Actuators B 2006, 115, 134-139. [CrossRef]

12. Zhang, X.; Tang, K.; Zheng, X. Electrospinning and Crosslinking of COL/PVA Nanofiber-microsphere Containing Salicylic Acid for Drug Delivery. J. Bionic Eng. 2016, 13, 143-149. [CrossRef]

13. Habiba, U.; Islam, M.S.; Siddique, T.A. Adsorption and photocatalytic degradation of anionic dyes on Chitosan/PVA/Na-Titanate/TiO 2 composites synthesized by solution casting method. Carbohydr. Polym. 2016, 149, 317-331. [CrossRef] [PubMed]

14. Pisuchpen, T.; Chaim-Ngoen, N.; Intasanta, N. Tuning Hydrophobicity and Water Adhesion by Electrospinning and Silanization. Langmuir 2011, 27, 3654-3661. [CrossRef]

15. Xie, Y.; Hill, C.A.S.; Xiao, Z. Silane coupling agents used for natural fiber/polymer composites: A review. Compos. Part A Appl. Sci. Manuf. Inc. Compos. Compos. Manuf. 2010, 41, 806-819. [CrossRef]

16. Herrera-Franco, P.; Valadez-Gonzalez, A. A study of the mechanical properties of short natural-fiber reinforced composites. Compos. Part B Eng. 2005, 36, 597-608. [CrossRef]

17. Ion, A.; Parvulescu, V.; Jacobs, P.; De Vos, D. Sc and Zn-catalyzed synthesis of cyclic carbonates from CO2 and epoxides. Appl. Catal. A Gen. 2009, 363, 40-44. [CrossRef]

18. Li, Y.Y.; Yan, B.; Guo, L.; Li, Y.J. Ternar rare earth sulfoxide-functionalized mesoporous hybrids Phen-RE(OBDS(BSAB) $)_{3}-\mathrm{SBA}-15(\mathrm{RE}=\mathrm{Eu}, \mathrm{Tb})$ : Coordination bonding assembly, characterization, and photoluminescence. Microporous Mesoporous Mater. 2012, 148, 73-79. [CrossRef]

19. Binnemans, K. ChemInform Abstract: Lanthanide-Based Luminescent Hybrid Materials. Cheminform 2009, 40, 4283-4374. [CrossRef]

20. Fadeyev, E.; Smola, S.; Snurnikova, O.; Korovin, O.; Rusakova, N. Luminescent sol-gel materials based on lanthanide aminopolycarboxylates ( $\mathrm{Ln}=\mathrm{Nd}, \mathrm{Eu}, \mathrm{Tb}, \mathrm{Yb})$. J. Sol Gel Sci. Technol. 2013, 68, 479-487. [CrossRef]

21. Xu, Q.J.; Wang, D.; Ren, S.X.; Fang, G.Z. Investigation of preparation and luminescent of europium complexes modified by silane. J. Funct. Mater. 2015, 46, 139-143.

22. Wang, Y.; Zhang, W.J.; Li, J.L.; Fu, J. A novel LEuH/PVA luminescent hydrogel with ammonia response and self-recovery luminescence behavior. Arab. J. Chem. 2019, 43, 5133-5138. [CrossRef]

23. Shao, C.; Kim, H.Y.; Gong, J. Fiber mats of poly (vinyl alcohol)/silica composite via electrospinning. Mater. Lett. 2003, 57, 1579-1584. [CrossRef]

24. Nagaoka, Y.; Adachi, S. Photoluminescent properties of $\mathrm{NaCl}: \mathrm{Ce}^{3+}$ phosphor synthesized using antisolvent crystallization. J. Lumin. 2014, 145, 797-802. [CrossRef]

25. Bünzli, J.C.G. Lanthanide Luminescence for Biomedical Analyses and Imaging. Chem. Rev. 2010, 110, 2729-2755. [CrossRef]

26. Zhao, B.; Chen, X.Y.; Cheng, P. Coordination Polymers Containing 1D Channels as Selective Luminescent Probes. J. Am. Chem. Soc. 2004, 126, 15394-15395. [CrossRef]

27. Moore, E.G.; Samuel, A.P.S.; Raymond, K.N. From Antenna to Assay: Lessons Learned in Lanthanide Luminescence. Acc. Chem. Res. 2009, 42, 542-552. [CrossRef]

28. Craig, P.M.; Benjamin, S.M.; Robert, P.; David, P. Cell-Penetrating Metal Complex Optical Probes: Targeted and Responsive Systems Based on Lanthanide Luminescence. Acc. Chem. Res. 2009, 42, 925-937.

29. Petoud, S.; Cohen, S.M.; Bünzli, J.C.G.; Raymond, K.N. Stable Lanthanide Luminescence Agents Highly Emissive in Aqueous Solution Multidentate 2-Hydroxyisophthalamide Complexes of $\mathrm{Sm}^{3+}, \mathrm{Eu}^{3+}, \mathrm{Tb}^{3+}$, $\mathrm{Dy}^{3+}$. J. Am. Chem. Soc. 2003, 125, 13324-13325. [CrossRef]

30. Chi, Y.; Fu, L.M.; Wang, Y.; Zhang, J.P. A Highly Luminescent Europium Complex Showing Visible-Light-Sensitized Red Emission: Direct Observation of the Singlet Pathway. Angew. Chem. 2004, 116, 5120-5123.

31. Min, L.; Paul, R.S. Luminescent Polyaminocarboxylate Chelates of Terbium and Europium: The Effect of Chelate Structure. J. Am. Chem. Soc. 1995, 117, 8132-8138.

32. Gao, J.; Li, Q.; Wang, C.H.; Tan, H.L. Ratiometric detection of hydroxy radicals based on functionalized europium (III) coordination polymers. Mikrochim. Acta Int. J. Phys. Chem. Methods Anal. 2017, 185, 1-9. [CrossRef] [PubMed] 
33. Li, Q.; Li, T.; Wu, J. Luminescence of Europium (III) and Terbium (III) Complexes Incorporated in Poly (Vinyl Pyrrolidone) Matrix. J. Phys. Chem. B 2001, 105, 12293-12296. [CrossRef]

34. Topilova, Z.M.; Meshkova, S.B.; Dotsenko, V.P. Sensitization of Luminescence of Europium Compounds on Solid Matrices by Terbium (III) Ions. J. Appl. Spectrosc. 2004, 71, 253-256. [CrossRef]

(C) 2020 by the authors. Licensee MDPI, Basel, Switzerland. This article is an open access article distributed under the terms and conditions of the Creative Commons Attribution (CC BY) license (http://creativecommons.org/licenses/by/4.0/). 